\title{
Study of Traumatic Head Injuries Using Computed Tomography
}

\author{
Samih Kajoak ${ }^{1}$, Hamid Osman ${ }^{1 *}$, Caroline E. Ayad ${ }^{2}$, Alamin Musa ${ }^{3}$, Mohammed Yousef ${ }^{4}$, \\ Nahla L. Faizo ${ }^{1}$, Bushra Abdel Malik ${ }^{5}$ \\ ${ }^{I}$ Taif University, College of Applied Medical Sciences, Department of Radiological Sciences, KSA \\ ${ }^{2}$ College of Medical Radiological Sciences, Sudan University of Science and Technology, Khartoum, Sudan \\ ${ }^{3}$ King Khalid University, College of Applied Medical Sciences, Department of Diagnostic Radiology Sciences, KSA \\ ${ }^{4}$ Batterji Medical College, Radiological Sciences Program, KSA \\ ${ }^{5}$ Hail University, College of Applied Medical Sciences, Department of Diagnostic Radiology Sciences, KSA
}

\begin{abstract}
The aim of this retrospective research was to study traumatic head injury (THI) using CT scan and to classify the types of head trauma fractures and types of hemorrhages.

Methods and Results: The current study included 53 THI patients (43/81.1\%) males and 10/18.9\% females) with positive and negative CT scan findings. A complete clinical history and patients' data were taken from CT reports, which included age, gender, type of trauma, associated injury, and CT findings with their percentages. The study was carried out in Taif city in King Abdelaziz Hospital and King Faisal Hospital.

The distribution of various etiologies of THI has shown that the most common etiology was road traffic accident (RTA) (45.3\%). The typical age for THI was between 21 to 30 years old $(26.4 \%)$. The distribution of the traumatic causes for each age group showed that the typical age for RTA was the age group of 11-20 years (33.3\%), for falls - the age groups of 2-10 years $(33.3 \%)$ and over 60 years of age $(33.3 \%)$. The frequency of various CT findings of THI was as follows: intracranial hemorrhage $(56.6 \%)$, fracture $(39.6 \%)$, pneumocephalus $(22.6 \%)$, contusion $(22.6 \%)$, foreign body $(11.3 \%)$, and proptosis $(3.8 \%)$. The distribution of fracture cases, according to their types, was as follows: a linear fracture $(76.2 \%)$, comminuted fracture $(23.8 \%)$, basilar fracture (14.3\%), and depressed fracture (9.5\%). The frontal bone was the most affected site with fractures (30.7\%).

Conclusion: CT is an appropriate clinical modality used in the management of THI patients in the emergency department. CT has the advantage of being fast, safe, available, sensitive to most acute post-traumatic injuries, accurate in identifying the head abnormalities such as fractures and hemorrhage during the first 24 hours after injury, which is beneficial in the early assessment, therapy planning, monitoring, and long-term patient care.(International Journal of Biomedicine. 2021;11(1):82-86.)
\end{abstract}

Key Words: computed tomography $\bullet$ traumatic head injury $\bullet$ road traffic accident

For citation: Kajoak S, Osman H, Ayad CE, Musa A, Yousef M, Faizo NL, Malik BA. Study of Traumatic Head Injuries Using Computed Tomography. International Journal of Biomedicine. 2021;11(1):82-86. doi:10.21103/Article11(1)_OA14

\section{Abbreviations}

CT, computed tomography; THI, traumatic head injury; TBI, traumatic brain injury; MRI, magnetic resonance imaging; RTA, road traffic accident.

\section{Introduction}

Traumatic head injury (THI) is one of the most common causes of death and disability in children and adults worldwide. In some literature sources, ${ }^{(1,2)}$ the terms "traumatic head injury" and "traumatic brain injury" have been used interchangeably.
Therefore, head injuries are characterized as brain injuries caused by external mechanical force, such as blast waves, rapid acceleration or deceleration, or projectile penetration, leading to temporary or permanent loss of brain function. ${ }^{(3)}$ They account for a significant number of hospitalizations and a high degree of mortality worldwide. Statistically, the Center 
for Disease Control and Prevention (CDC) has estimated that annually, about 1.5 million Americans survive a traumatic brain injury (TBI). Among these, approximately 230,000 are hospitalized. In 2000, there were 10,958 TBI diagnoses. In 2015, this number jumped to 344,030. Mortality across all TBI severities is approximately $3 \%$, yet morbidity is more difficult to estimate. ${ }^{(4)}$ The primary external cause of the head trauma, and therefore TBI, are road traffic accidents (RTAs) (accounting for approximately $60 \%$ of the cases), falls $(20 \%$ $30 \%)$, violence $(10 \%)$, and workplace and sports related activities $(10 \%) .{ }^{(5-7)}$ Therefore, all THIs need prompt diagnosis by a doctor with expertise in evaluating head injuries. A neurological examination will evaluate sensory and motor skills and the functioning of one or more cranial nerves. It will also check hearing and speech, coordination and balance, mental status, and behavior or mood changes, among other abilities. Subsequently, early diagnosis and correct supervision of THIs can meaningfully change their progression, especially within 48 hours of injury. ${ }^{(8)}$ The severity of TBIs can be classified into mild, moderate, and severe injuries, according to the Glasgow Coma Scale (GCS), duration of loss of consciousness, and duration of posttraumatic amnesia. ${ }^{(9)}$

Health care professionals will use head scans to evaluate the severity of the primary head injuries and decide if surgery will be required to help treat any damage to the brain. Generally, conventional skull radiography was a commonly used radiological technique in head trauma situations, but currently, cross-sectional imaging generated during CT scans has become the preferred option, particularly in THI management, for a number of reasons. CT has fast examination time, wide availability, and is highly sensitive and accurate for detecting acute intra-axial and extra-axial hemorrhage. CT allows a clear presentation of the brain or bone injuries as seen in skull, temporal bone, facial, and orbital fractures, and lack of contraindications to metallic foreign bodies. It is also cheaper than MRI. ${ }^{(10)}$

CT scan is the primary modality of choice for accurate diagnosis of patients with THI, which helps in appropriate treatment and prompt intervention in surgery areas.

The aim of this retrospective research was to study THI using CT scan and to classify the types of head trauma fractures and types of hemorrhages.

\section{Materials and Methods}

The current study included 53 THI patients (43/81.1\%) males and 10/18.9\% females; the age range 2-91 years.) with positive and negative CT scan findings. A complete clinical history and patients' data were taken from CT reports, which included age, gender, type of trauma, associated injury, and CT findings with their percentages. The study was carried out in Taif city in King Abdelaziz Hospital and King Faisal Hospital.

We obtained 5-mm-thick axial and 10-mm-thick axial sections using the multislice spiral CT technique. Bone algorithms with wide window settings were studied to visualize any fracture of the skull. Soft tissue and brain window were studied to visualize any hemorrhage or contusions. No contrast material was administrated (Figure 1). Statistical analysis was performed using statistical software package SPSS version 16.0 (SPSS Inc, Chicago, IL).
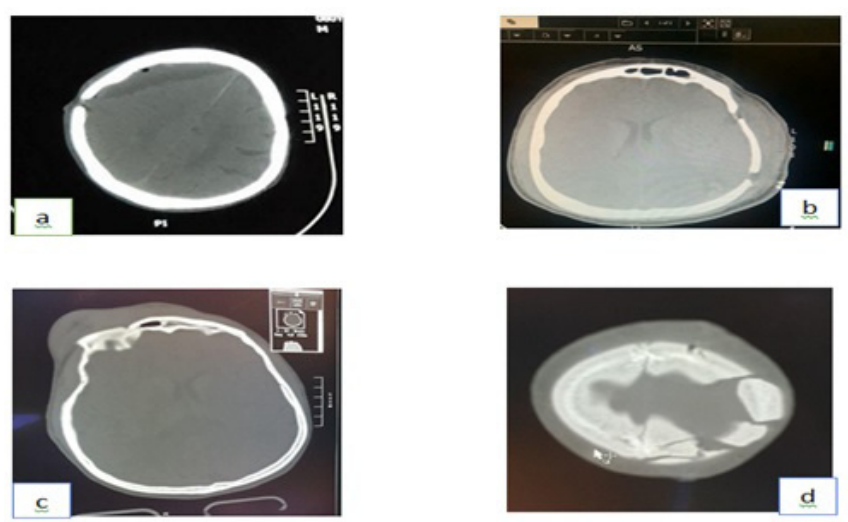

Fig. 1. Various forms of skull fracture. (a) Linear fracture of the right parietal bone with chronic subdural hematoma. (b) Linear fracture of the left parietal bone with excessively soft tissue swelling. (c) Depressed fracture of the frontal bone with overlying soft tissue swelling. (d) Comminuted and displaced fracture of parietal bones.

\section{Results}

The distribution of various etiologies of THI has shown that the most common etiology was an RTA (45.3\%), followed by falls $(28.3 \%)$, an assault $(18.9 \%)$, gunshot $(1.88 \%)$, and other $(5.7 \%)$.

The typical age for THI was between 21 to 30 years old (26.4\%), followed by 11 to 20 years $(16.9 \%)$, and other age groups (Figure 2).

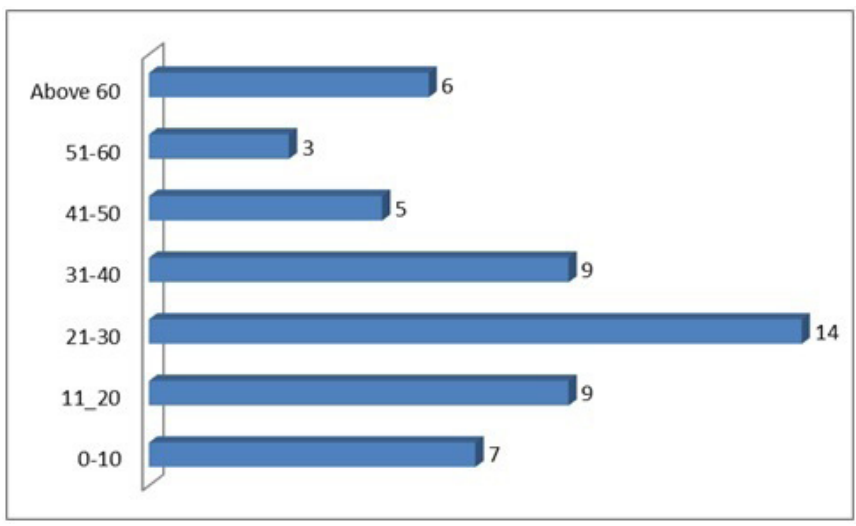

Fig. 2. Age distribution of patients

The distribution of the traumatic causes for each age group is shown in Table 1. The typical age for RTA was the age group of $11-20$ years $(33.3 \%)$, for falls - the age groups of $0-10$ years $(33.3 \%)$ and over 60 years of age $(33.3 \%)$.

Figure 3 shows the frequency of various CT findings of THI. There were $30(56.6 \%)$ patients with intracranial hemorrhage, 26(49.1\%) patients with fracture, 12(22.6\%) patients with pneumocephalus, $12(22.6 \%)$ patients with 
contusion, 6(11.3\%) patients with foreign body, and $2(3.8 \%)$ patients with proptosis. Most patients had several complications at the same time.

\section{Table 1.}

The distribution of the traumatic causes for each age group

\begin{tabular}{|c|c|c|c|c|c|c|}
\hline \multirow{2}{*}{ Age groups } & \multicolumn{5}{|c|}{ Traumatic causes } & \multirow{2}{*}{ n(\%) } \\
\cline { 2 - 6 } & $\begin{array}{c}\text { RTA } \\
(\mathrm{n}=24)\end{array}$ & $\begin{array}{c}\text { Falls } \\
(\mathrm{n}=15)\end{array}$ & $\begin{array}{c}\text { Assault } \\
(\mathrm{n}=10)\end{array}$ & $\begin{array}{c}\text { Gunshot } \\
(\mathrm{n}=1)\end{array}$ & $\begin{array}{c}\text { Other } \\
(\mathrm{n}=3)\end{array}$ & \\
\hline $2-10$ & 2 & 5 & 0 & 0 & 0 & $7(13.2 \%)$ \\
\hline $11-20$ & 8 & 0 & 0 & 0 & 1 & $9(16.98 \%)$ \\
\hline $21-30$ & 6 & 1 & 7 & 0 & 0 & $14(26.4 \%)$ \\
\hline $31-40$ & 4 & 1 & 2 & 1 & 1 & $9(16.98 \%)$ \\
\hline $41-50$ & 2 & 1 & 1 & 0 & 1 & $5(9.4 \%)$ \\
\hline $51-60$ & 1 & 2 & 0 & 0 & 0 & $3(5.7 \%)$ \\
\hline Above 60 & 1 & 5 & 0 & 0 & 0 & $6(11.3 \%)$ \\
\hline$P$-value & $>0.05$ & 0.011 & $>0.05$ & $>0.05$ & $>0.05$ & $53(100 \%)$ \\
\hline
\end{tabular}

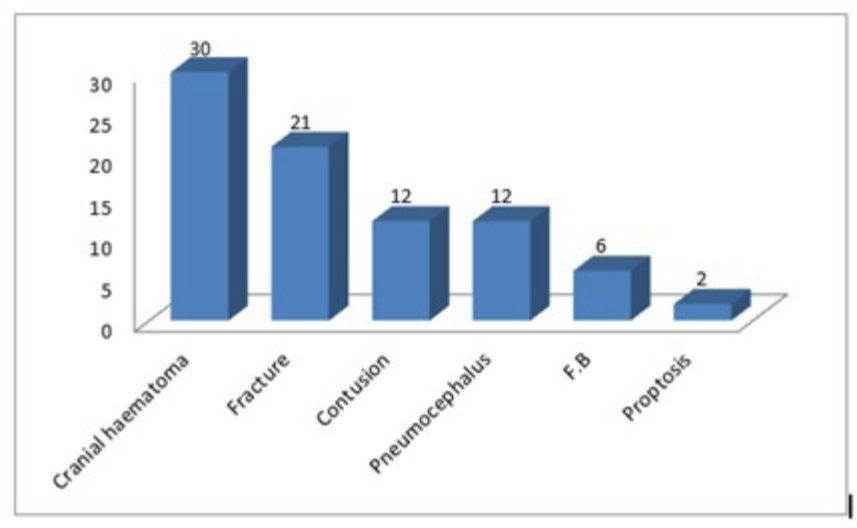

Fig. 3. The frequency of various CT findings of THI

The distribution of cranial hemorrhage cases, according to its types, was as follows: subgaleal hematoma (SGH-40.5\%), subdural hematoma (SDH-23.8\%), epidural hematoma (EDH$19.0 \%$ ), subarachnoid hematoma (SAH-11.9\%), intracerebral hematoma (ICH-2.4\%), and intraventricular hematoma (IVH2.4\%) (Fig.4).

The distribution of fracture cases, according to their types, was as follows: a linear fracture $(76.2 \%)$, comminuted fracture $(23.8 \%)$, basilar fracture $(14.3 \%)$, and depressed fracture $(9.5 \%)$. Sometimes the patient had more than one type of fracture.

The frontal bone was the most affected site with fractures $(30.7 \%)$, followed by parietal bone $(19.2 \%)$, nasal bone (15.3\%), occipital bone (11.5\%), temporal bone (11.5\%), zygomatic arch (7.7\%), and sphenoid bone (3.8\%) (Table 2). There was no significant relationship between site and type of fracture.

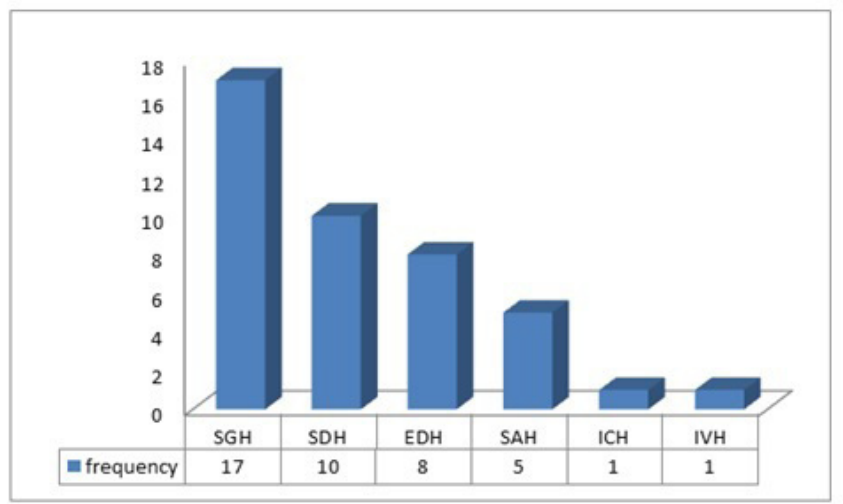

Fig. 4. The distribution of cranial hemorrhage cases, according to its types.

Table 2

The relationship between site and type of fracture.

\begin{tabular}{|c|c|c|c|c|c|}
\hline \multirow{2}{*}{ Site of fracture } & \multicolumn{4}{|c|}{ Type of fracture } & \multirow{2}{*}{ n $(\%)$} \\
\hline & linear & comminuted & basilar & depressed & \\
\hline Frontal bone & 6 & 0 & 1 & 1 & $8(30.7 \%)$ \\
\hline Parietal bone & 1 & 3 & 0 & 1 & $5(19.2 \%)$ \\
\hline Occipital bone & 3 & 0 & 0 & 0 & $3(11.5 \%)$ \\
\hline Temporal bone & 2 & 0 & 1 & 0 & $3(11.5 \%)$ \\
\hline Zygomatic arch & 1 & 1 & 0 & 0 & $2(7.7 \%$ \\
\hline Nasal bone & 3 & 1 & 0 & 0 & $4(15.3 \%)$ \\
\hline Sphenoid bone & 0 & 0 & 1 & 0 & $1(3.8 \%)$ \\
\hline Total number & 16 & 5 & 3 & 2 & $26(100 \%)$ \\
\hline
\end{tabular}

\section{Discussion}

THI is an increasingly worldwide health concern. Precise assessment of patients suffering from head trauma using a CT scan is very useful in diagnosis and treatment. In the current manuscript of 53 cases listed, $43(81.1 \%)$ are males, and only $10(18.9 \%)$ are females, showing male preponderance in THI. This may be attributed to the fact that males remain out of their homes more commonly in our local community. This result is similar to the findings in the USA. ${ }^{(11)}$

According to our study, RTA is the more common etiology of THI $(45.3 \%)$. These results were close to those obtained by Bordignon et al. ${ }^{(12)}$ and Agrawal et al. ${ }^{(13)}$ 
The majority of patients in our study were seen to be in the third decade of life (26.4\%) followed by the second decade and fourth decade, which together accounted for $16.97 \%$ of cases. These age groups are the more commonly involved groups in society, which spend the majority of the day outside homes, involved in social and economic life. Therefore, they are more prone to RTA with THI. These results were similar to those obtained by other researchers. ${ }^{(14,15)}$

Falls were the most common etiological factor of THI for the age groups of 2-10 years (33.3\%) and over 60 years of age $(33.3 \%)$.

In our study, the cranial hemorrhage (extracranial and intracranial) was the most common finding, constituting $56.6 \%$. Extracranial hemorrhage is composed of caput succedaneum, cephalohematoma, and subgaleal hematoma. Intracranial hemorrhage is composed of subdural hematoma, epidural hematoma, subarachnoid hematoma, intracerebral hematoma, and interventricular hematoma. In our study, the most frequent hematoma type in THI was subgaleal hematoma (56.1\%). The study carried out by Zimmerman et al. ${ }^{(5)}$ found that the most frequent intracranial lesion in 286 patients was hemorrhagic contusions.

The results of our study showed that fracture cases accounted for $49.1 \%$ of total THI complications. In the study conducted by Yattoo et al., ${ }^{(16)}$ the CT results in 547 patients showed a skull fracture in only $8.9 \%$ of cases. In our series, the distribution of fracture cases according to their types revealed that a linear fracture was more common $(76.2 \%)$, and the frontal bone was the most affected site for fracture $(30.7 \%)$. Our results showed the frequent presence of combined THI complications. For example, $61.9 \%$ of skull fractures have been associated with cranial hemorrhage and $58.3 \%$ pneumocephalus with cranial hemorrhage. About 15.1\% of cases included fractures, cranial hemorrhage, and contusion.

In the time instantly after head trauma, a CT scan is most widely used to diagnose severe problems that could be life-threatening as well as to check whether there are metallic foreign bodies. MRI anatomical imaging is very effective and precise for cerebral pathology diagnosis in THI patients to determine that there are no metallic bodies involved in the injury. Nonetheless, the CT scan is the primary imaging tool of choice in the first 24 hours following injury. ${ }^{(17-19)}$ MRI is mostly considered superior to CT after 48 to 72 hours. While CT scan is effective in detecting bone disease and other forms of early bleeds, the accuracy of MRI to diagnose hematomas increases with time as blood composition changes. ${ }^{(20)}$

In conclusion, $\mathrm{CT}$ is an appropriate clinical modality used in the management of THI patients in the emergency department. CT has the advantage of being fast, safe, available, sensitive to most acute post-traumatic injuries, accurate in identifying the head abnormalities such as fractures and hemorrhage during the first 24 hours after injury, which is beneficial in the early assessment, therapy planning, monitoring, and long-term patient care. Furthermore, CT should only be done when clinically indicated to help minimize costs and prevent unneeded radiation exposure.

Our study also concludes that RTA is the chief cause of THI and that head injuries are generally more frequent in males than in females and in the most active age group relative to other age groups; in addition, the most frequent fracture type for THI is a linear fracture.

\section{Competing Interests} interests.

The authors declare that they have no competing

\section{References}

1. Johnson KM. The hazards of stopping a brain in motion: evaluation and classification of traumatic brain injury. Virtual Mentor. 2008 Aug 1;10(8):516-20. doi: 10.1001/virtualmento r.2008.10.8.cprl1-0808.

2. Ghebrehiwet M, Quan LH, Andebirhan T. The profile of CT scan findings in acute head trauma in Orotta Hospital, Asmara, Eritrea. JEMA. 2009;4:5-8.

3. Maas AI, Stocchetti N, Bullock R. Moderate and severe traumatic brain injury in adults. Lancet Neurol. 2008 Aug;7(8):728-41. doi: 10.1016/S1474-4422(08)70164-9.

4. Georges A, Booker JG. Traumatic Brain Injury. 2020 Nov 19. In: StatPearls [Internet]. Treasure Island (FL): StatPearls Publishing; 2020 Jan-. PMID: 29083790.

5. Zimmerman RA, Bilaniuk LT, Gennarelli T, Bruce D, Dolinskas C, Uzzell B. Cranial computed tomography in diagnosis and management of acute head trauma. AJR Am J Roentgenol. 1978 Jul;131(1):27-34. doi: 10.2214/ajr.131.1.27. 6. Hyder AA, Wunderlich CA, Puvanachandra P, Gururaj G, Kobusingye OC. The impact of traumatic brain injuries: a global perspective. NeuroRehabilitation. 2007;22(5):341-53.

7. Asaleye CM, Famurewa OC, Komolafe EO, Komolafe MA, Amusa YB. The pattern of Computerized Topographic findings in moderate and severe head injuries in ILE- IFE, Nigeria. West Afr J Radiol. 2005;12:8-13.

8. Sosin DM, Sniezek JE, Waxweiler RJ. Trends in death associated with traumatic brain injury, 1979 through 1992. Success and failure. JAMA. 1995 Jun 14;273(22):1778-80.

9. Sternbach GL. The Glasgow coma scale. J Emerg Med. 2000 Jul;19(1):67-71. doi: 10.1016/s0736-4679(00)00182-7. PMID: 10863122.

10. Majdan M, Mauritz W, Brazinova A, Rusnak M, Leitgeb J, Janciak I, Wilbacher I. Severity and outcome of traumatic brain injuries (TBI) with different causes of injury. Brain Inj. 2011;25(9):797-805. doi: 10.3109/02699052.2011.581642.

11. Edelman RR, Hesselink JR, Zlatkin MB, Crues JV., III. Clinical Magnetic Resonance Imaging. New York, NY: Elsevier; 2005.

12. Bordignon KC, Arruda WO. CT scan findings in mild head trauma: a series of 2,000 patients. Arq Neuropsiquiatr. 2002 Jun;60(2-A):204-10. doi: 10.1590/s0004$282 \times 2002000200004$.

13. Agrawal A, Agrawal CS, Kumar A, Lewis O, Malla G, Khatiwada R, Rokaya P. Epidemiology and management of paediatric head injury in eastern Nepal. Afr J Paediatr Surg. 2008 Jan-Jun;5(1):15-8. doi: 10.4103/0189-6725.41630.

*Corresponding author: Hamid Osman. Taif University, College of Medical Applied Sciences, Department of Diagnostic Radiology Sciences. Taif, Saudi Arabia.E-mail: hamidsssan@yahoo. com 
14. Norlund A, Marké LA, af Geijerstam JL, Oredsson S, Britton M; OCTOPUS Study. Immediate computed tomography or admission for observation after mild head injury: cost comparison in randomised controlled trial. BMJ. 2006 Sep 2;333(7566):469. doi: 10.1136/bmj.38918.659120.4F.

15. Jeret JS, Mandell M, Anziska B, Lipitz M, Vilceus AP, Ware JA, Zesiewicz TA. Clinical predictors of abnormality disclosed by computed tomography after mild head trauma. Neurosurgery. 1993 Jan;32(1):9-15; discussion 15-6. doi: 10.1227/00006123-199301000-00002.

16. Yattoo G, Tabish A. The profile of head injuries and traumatic brain injury deaths in Kashmir. J Trauma Manag Outcomes. 2008 Jun 21;2(1):5. doi: 10.1186/1752-2897-2-5. 17. Glauser J. Head injury: which patients need imaging?
Which test is best? Cleve Clin J Med. 2004 Apr;71(4):353-7. doi: $10.3949 /$ ccjm.71.4.353.

18. Garnett MR, Cadoux-Hudson TA, Styles P. How useful is magnetic resonance imaging in predicting severity and outcome in traumatic brain injury? Curr Opin Neurol. 2001 Dec;14(6):753-7. doi: 10.1097/00019052-200112000-00012.

19. Kampfl A, Schmutzhard E, Franz G, Pfausler B, Haring HP, Ulmer H, Felber S, Golaszewski S, Aichner F. Prediction of recovery from post-traumatic vegetative state with cerebral magnetic-resonance imaging. Lancet. 1998 Jun 13;351(9118):1763-7. doi: 10.1016/S0140-6736(97)10301-4. 20. Lee B, Newberg A. Neuroimaging in traumatic brain imaging. NeuroRx. 2005 Apr;2(2):372-83. doi: 10.1602/ neurorx.2.2.372. 